\title{
THE COUPLING OF THERMOCHEMISTRY \\ AND PHASE DIAGRAMS FOR GROUP III-V SEMICONDUCTOR SYSTEMS
}

Progress Report

September 1, 1989 - April 30, 1990

T.J. Anderson.

Department of Chemical Engineering

University of Florida

Gainesville, FL 32611

\section{PREPARED FOR THE U.S. DEPARTMENT OF ENERGY UNDER GRANT NUMBER DE-FG05-86ER 45276}

\section{DISCLAIMER}

This report was prepared as an account of work sponsored by an agency of the United States Government. Neither the United States Government nor any agency thereof, nor any of their employees, makes any warranty, express or implied, or assumes any legal liability or responsibility for the accuracy, completeness, or usefulness of any information, apparatus, product, or process disclosed, or represents that its use would not infringe privately owned rights. Reference herein to any specific commercial product, process, or service by trade name, trademark, manufacturer, or otherwise does not necessarily constitute or imply its endorsement, recommendation, or favoring by the United States Government or any agency thereof. The views and opinions of authors expressed herein do not necessarily state or reflect those of the United States Government or any agency thereof.

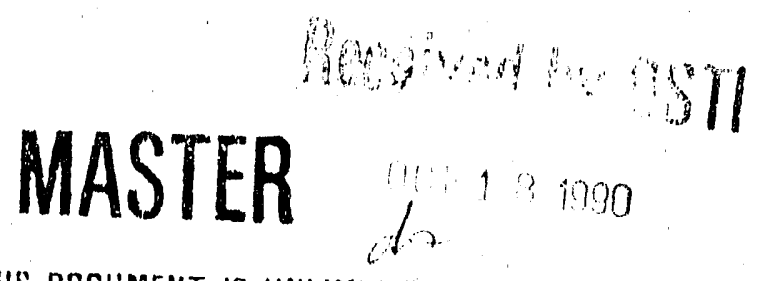


Table of Contents

Project Summary $\quad \ldots \ldots \ldots \ldots \ldots \ldots \ldots \ldots \ldots \ldots \ldots \ldots$

List of Publications $\quad \ldots \ldots \ldots \ldots \ldots \ldots \ldots \ldots \ldots \ldots \ldots$

List of Manuscripts in Preparation $\quad \ldots \ldots \ldots \ldots \ldots \ldots \ldots \ldots \ldots \ldots \ldots$

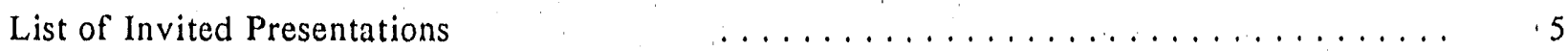

List of Conference Presentations $\quad \ldots \ldots \ldots \ldots \ldots \ldots \ldots \ldots \ldots \ldots$

List of University and Industrial Seminars $\quad \ldots \ldots \ldots \ldots \ldots \ldots \ldots \ldots \ldots \ldots \ldots$

Appendix I. Solid-State Electrochemical Study of the $\quad \ldots \ldots \ldots \ldots$

Appendix II. Solid-State Electrochemical Study of the $\quad \ldots \ldots \ldots \ldots \ldots \ldots$ Al-Sb System

Appendix III. Assessment and Calculation of the Thermochemical . . . . . . . 66 Properties and Phase Diagrams for the Al-In and Al-Sb Systems

Appendix IV. Extrapolation and Optimization of the

Appendix V. Solid-State Electrochemical Study of the Liquid Antimony-Tellurium System 


\section{Project Summary}

Progress in the first year of the renewal and fourth year of the program has primarily occurred in the experimental area and subsequent assessment of binary and ternary systems.

Thermodynamic studies of the Al-In and Al-Sb systems have been carried out using solid electrolyte galvanic cells. Using the sensitive coulometric titration technique, aluminum activities were obtained for both systems. In addition, liquidus data were obtained for the Al-Sb system, and the Gibbs energy of formation of AlSb was determined. A detailed description of the work for the Al-In system is given in Appendix I while that for the Al-Sb system in Appendix II.

For the Al-Sb system, the coulometric titration technique was also used to investigate, for the first time, the very narrow region of homogeneity in the AlSb compound. The width of the compound was found to be 0.002 mole fraction at $850^{\circ} \mathrm{C}$, and the deviation from stoichiometry was determined to occur primarily on the Al-rich side.

The experimental data obtained in this study were used along with the available literature data in the critical assessment and calculation of the Al- $\mathrm{In}$ and $\mathrm{Al}-\mathrm{Sb}$ systems. The results are given in Appendix III. The Al-In was successfully modeled using the Redlich-Kister polynomial to describe the liquid phase, and the $\mathrm{Al}-\mathrm{Sb}$ system was described with the associate model as well as the polynomial model. In addition, the Wagner-Schottky model was able to give a description of the AISb homogeneity region that was consistent with the solid-phase titration data obtained in this study.

The calculated binary descriptions for the Al-In and Al-Sb systems were used in the calculation of the Al-In-Sb system. The ternary description using only the binary parameters gave a very reasonable fit to the available Al-In-Sb data. Two.ternary parameters were determined from optimization of the ternary data, and the resulting Al-In-Sb description agreed excellently with the ternary data. The results of this study are given in Appendix IV and will be presented at the 1990 CALPHAD meeting. 
The activity of $\mathrm{Sb}$ in liquid $\mathrm{Sb}-\mathrm{Te}$ mixtures was determined in a solid-state galvanic cell over the entire composition range. Slight positive deviations from ideal behavior were measured in Sb-rich compositions while negative deviations were exhibited throughout most of the composition range studied. The experimental results for the $\mathrm{Sb}-\mathrm{Te}$ system are given in Appendix $\mathrm{V}$. This segment of the project was performed by Professor Yves Feutalis during a two month visit to our laboratory.

In addition to the completed studies summarized above, work was initiated in other projects. These projects inolude: measurement of the activity in Ga-As melts (2 cells studied to date), assessment of the $\mathrm{Ga}-\mathrm{Sb}, \mathrm{In}-\mathrm{Sb}$ and $\mathrm{Sb}$-Te systems (literature surveyed and initial assessment made), and the computation of reaction equilibria in the In-Ga-As-P-Cl-H system (effect of $\mathrm{HCl}$ on the alloy composition studied). As described in the proposed activities for the next funding period, this work will continue. 
List of Publications Acknowledging Support of DOE (9/1/86 present)

1. "Calorimetric and Knudsen Effusive Studies of the Thermochemical Properties of Ga $\ln _{1-x} P$ Alloys", T.J. Anderson, C. Colinet, C. Chatillon and M. Tmar, J. Crystal Growth, 8.3, 2.52-260 (1987).

2. "Thermodynamics of the Ga-Tl and In-TI Systems", J.R. Krawczyk and T.J. Anderson. TMS Tech. Paper No. A87-25 (1987).

3. "A Thermodynamic Analysis of CVD of Ge-Si in the Ge-Si-Cl-H System", S. Chang, D. Unzicker and T.J. Anderson. Proc. Tenth Int. Conf. on CVD, 122-134 (1987).

4. "Liquid Phase Epitaxy and Phase Diagrams of Compound Semiconductors", T.J. Anderson. Chapter in Advances in Chemistry Series No. 221, Chemical Engineerirg in Electronic Materials Processing, 105-170 (1989).

5. "Assessment of the Al-Sb System", C.A. Coughanowr, U.R. Kattner and T.J. Anderson, CALPHAD, 14, 195-204 (1990).

6. "A Thermodynamic Analy's of Germanium Nitride CVD", F, DeFoort, J.L. Ponthenier and T.J. Anderson, High Temp. Sci. (1990).

7. "The Ga-In System", T.J. Anderson and I. Ansara. Accepted Bull. Alloy Phase Diagrams:

8. "The Ga-Sn System", T.J. Anderson and I. Ansara. Accepted Bull. Alloy Phase Diagrams.

9. "The In-Sn System", T.J. A Iderson and I. Ansara, submitted to Bull. Alloy Phase Diagrams. 
List of Manuscripts in Preparation to Acknowledge Support of DOE

1. "The Ga-In-Sn System". To be submitted to Bull. Alloy Phase Diagrams.

2. "Solid State Electrochemical Study of the Ga-Bi System". To be submitted to J. Chem. Thermodynamics.

3. "Solid State Electrochemical Study of the In-Bi System". To be submitted to J. Less-Common Met.

4. "Thermodynamic Analysis of Chemical Vapor Deposition of $\mathrm{Ga}_{\mathbf{x}} \ln _{1-\mathbf{x}}$ As by the Hydride Process". To be submitted to J. Crystal Growth.

5. "Solid State Electrochemical Measurement of the Al activity in Al-In Melts". To be submitted to J. Electrochem. Soc.

6. "Determination of the Range of Stoichiometry in AISb by Coulometric Titration". To be submitted to J. Crystal Growth.

7. "Experimental Determination of the Al Activity in Al-Sb(l) and the Gibbs Energy of Formation of AlSb". To be submitted to J. Chem. Thermodynamics.

8. "Solid State Electrochemical Study of the Liquid Sb-Te System". To be submitted to Iligh Temp. Sci.

9. "An Assessment of the Al-In-Sb System". To be submitted to CALPHAD. 
List of Technical Presentations Based on Work Supported by DOE (9/1/86-present)

1. "Calorimetric and Mass Spertrometer Studies of $\operatorname{lnGaAs}$ and InGaP Solid Solutions". Presented at NATO Workshop on InP, Horwichport, MA (1986).

2. "Thermodynamics of the Ga-Tl and In-Tl Systems". Presented at the TMS Annual Meeting, Denver, CO (1987).

3. "Phase Diagram and Thermochemistry of the $\mathrm{Al}_{x} \mathrm{Ga}_{y} \mathrm{In}_{1-x-y} \mathrm{Sb}$ System". Presented at CALPHAD XVI, Irsee, Germany (1987).

4. "Thermodynamic Analysis of $\mathrm{Si}_{x} \mathrm{Ge}_{1 \times x}$ Chemical Vapor Deposition". Presented at the 172nd Electrochemical Society Meeting, Honolulu, Hl (1987).

5. "Thermodynamics and Phase Equilibria Studies of the A.1-Sb System". Presented at the 174th Electrochemical Society Mecting, Chicngo, II (1988).

6. "Thermodynamics of Compound Semiconductors". Florida High Technology and Industry Council Conf., Tampa, FL (1988).

7. "Thermodynamic Analysis of Chemical Vapor Deposition of $\mathrm{Ga}_{x} \operatorname{In} n_{1-x}$ As by the Hydride Process". Presented at CALPHAD XVII, Berkeley, CA (1988).

8. "A Thermodynamic Analysis of Germanium Nitride CVD". Presented at 6th Int. Conf. on High Temp. Chem. of Inorganic Mat, Gaithersburg, MD (1989).

9. "Thermodynamic Investigation of the AI-In and Al-Sb Systems by Solid-State Electrochemistry". Presented at 6th Int. Conf, on High Temp. Chem. of Inorganic Mat., Gaithersburg, MD (1989).

10. "Solid-State Electrochemical Study of Liquid In-Bi Alloys". Presented at CALPHAD XVIII, Stockholm, Sweden (May, 1989).

11. "Complex Chemical Equilibrium Analysis of InP-based Vapor Phase Epitaxy". Presented at Nat. AlChE Meeting, Orlando, FL (i990).

12. "An Assessment of the Al-In-Sb System". To be presented at CALPHAD XIX, Norrdwijkerhout, Netherlands (1990). 
List of Invited Conference Presentations Acknowledging DOE Support ( $9 / 1 / 86$ to present)

1. "Liquid Phase Epitaxy and Phase Diagrams of Compound Scmiconductors". Invited presentation at the ACS Symp, on Processing Tech, and Electronic Device Manufacturing, Anaheim, CA (1986).

2. "Thermochemistry and Phase Diagrams of Ga-metal Systems". Presented at Symp, on Rare and Precious Metals, Albuquerque, NM (1988).

3. "Phenomena and Physical Property Needs in Semiconductor Materials Processing". Invitcd presentation at the 5th Int. Conf, on Fluid Prop. \& Phase Equilibria for Chem. Process Dosign, Banff, CANADA (1989).

4. "Chemical Vapor Deposition of Compound Semicond.cclors". Invited plenary lecture at Engineering Foundation Conference, Reaction Engineering III, Santa Barbara, CA (1990).

5. "Thermochemistry and Phase Diagrams of Compound Semiconductors". Invited keynote address at User Aspects of Phase Diagrams Conference, The Netherlands (1990). 
List of Invited University and Industrial Seminars Acknowledging DOE Support ( $9 / 1 / 86$ to present)

1. Michigan State University, Chemical Engineering Department, 1987

2. University of Pennsylvania, Chemical Engineering Department, 1987

3. Massachusetts Institute of Technology, Chemical Engineering Department, 1987

4. Virginia Polytechnic Institute and State University, Chemical Engineering Department, 1987

5. Purdue University, Chemical Engineering Department, 1988

6. Auburn University, Chemical Engineering Department, 1988

7. University of Alabama, Birmingham, Materials Science Department, 1988

8. University of Massachusetts, Chemical Engineering Department, 1989

9. University of Iowa, Chemical Engineering Department, 1989

10. University of South Florida, Physies Department; 1989

11. Georgia Institute of Technology, Chemical Engineering Depattment, 1990

12. Louisiana State University, Chemical Engineering Department, 1990

13. Princeton University, Chemical Engineering Department, 1990

1. E.I. duPot.t de Nemours \& Co., Wilmington, DE, 1986

2. General Electric, Schenectady, NY, 1987

3. Westinghouse R\&D Center, Pittsburgh, PA, 1987

4. Texas Instruments, Dallas, TX, 1989 


\section{A Continuation Proposal \\ Submitted to \\ U.S. Department of Energy}

The Coupling of Thermochemistry and

Phase Diagrams for Group III-V

Semiconductor Systems

Timothy J. Anderson

Department of Chemical Engineering

University of Florida

Gainesville, FL, 32611 


\section{Proposed Project Activities}

The types of activities being conducted in this research program can be grouped into 3 categories: 1) measurement of thermodynamic properties of compound semiconductor solid and liquid solutions 2) development of procedures for predicting multicomponent phase diagrams, including the examination of solution models and various standard states and methods of assessing existing literature data 3) application of these data, models and procedures to analysis of compound semiconductor processes. This program represents a vertically integrated study of the thermochemistry and phase diagrams of compound semiconductors. The measurement of key properties by solid state electrochemical techniques supports the fundamental framework that is being developed. These results will be uscful in establishing proper procedures for assessing and predicting multicomponent phase diagrams and their subsequent applications to processing these materials.

The progress of this project to date has been considerable. Property mensurements include: component activity measurements by a solid state galvanic cells in the binary liquid systems Sb-Te (1), $\mathrm{Ga}-\mathrm{Tl}(1), \operatorname{In}-\mathrm{Tl}(1), \mathrm{Al}-\mathrm{In}(1), \mathrm{Al}-\mathrm{Sb}(1), \mathrm{In}-\mathrm{Bi}(1)$ and $\mathrm{Ga}-\mathrm{Bi}(1)$; component activity measurements by $K$ nudsen-cell mass spectrometer in the pseudobinary solid solutions $\mathrm{Ga}_{x} I \mathrm{n}_{1 \cdot x}$ As and $G a_{x} I n_{1-x} P$; enthalpy of mixing measurements by solution calorimetry in the pseudobinary solid solutions $\mathrm{Ga}_{x} \operatorname{In}_{1}$. $x^{A s}$ and $\mathrm{Ca}_{x} \mathrm{In}_{1-x} \mathrm{P}$; and determination of the range of stoichiometry (coulometric titration), Gibbs energy of formation and component activities in the line compound AlSb. Procedures for calculating multicomponent phase diagrams have included an examination of standard states, development of a formalism for treating quaternary and pseudoternary systems, and assessment of the thermochemistry and phase diagrams for a variety of systems (Ga-Sb, In-Sb, Ga-In-Sb, Al-Sb, Al-In, Al-In-Sb, Al$\mathrm{Ga}-\mathrm{Sb}, \mathrm{Al}-\mathrm{Ga}-\mathrm{In}-\mathrm{Sb}, \mathrm{Ga}-\mathrm{Tl}, \mathrm{In}-\mathrm{Tl}, \mathrm{Ga}-\mathrm{Bi}, \mathrm{In}-\mathrm{Bi})$. The assessment work has used a maximum likelihood parameter estimation routine developed at Florida as well as the software packages ThermoCalc and Lukas. These results have been applied to processes that use an equilibrium boundary condition (i.e., bulk crystal growth and liquid phase epitaxy). In addition, the results have been used in an analysis of CVD by computation of complex reaction equilibrium with non-ideal 
condensed solutions. Both stoichiometric and non-stoichlometric codes have developed at Florida and Include a novel sensitivity analysis. Specifically, complex chemical equilibria have been computed in the following systems (as well as sub-systems) Ga-In-As-P-Cl-H, Si-Ge-Cl-H, Ge-N-Cl-H.

Plans for the next funding period includes a continuntion of all three activities, as outlined below:

1. We have shown on a theoretical basis that it is difficult to extract accurate thermodynamic information about solution behavior from phase diagram data alone. In the assessment work this fact appears as solution model parameters being highly correlated to each other and often in disagreement with activity and enthalpy data (when this data is available). This shortcoming is particularly obvious in the high vapor pressure systems (e.g., As and P containing solutions). As outlined in the original proposal, we plan to measure group III component activities in high vapor pressure systems by a solid-state galvanic cell for the first time. In order to prevent vaporization of the group $V$ element, we plan to use an immiscible liquid encapsulant $\left(\mathrm{B}_{2} \mathrm{O}_{3}\right)$. This technique has been used in bulk crystal growth of GaAs and InP by the Czochrolski method. A schematic of the cell for measuring the Ga activity in a Ga-As melt is:

$$
\mathrm{Ga}(1), \mathrm{Ga}_{2} \mathrm{O}_{3}(\mathrm{~s})\|\mathrm{YSZ}\| \mathrm{Ga}-\mathrm{As}(1), \mathrm{Ga}_{2} \mathrm{O}_{3}(\mathrm{~s}) \mid \mathrm{B}_{2} \mathrm{O}_{3}(1)
$$

An ancillary result from measurement of the temperature dependence is a liquidus temperature determination (as the temperature at which the measured enf changes slope). We have measured cell (1) with a pure $\mathrm{Ga}$ electrode and recorded zero potential, indicating $\mathrm{Ga}_{2} \mathrm{O}_{3}$ remains at unit activity. In addition, we have measured the composition $x_{G a}=0.75$; the results showing modernte negative deviations from ideal behavior. Plans for next year are to continue these measurements for several compositions in the Ga-As(1) system and then move to the In-As system. In the subsequent year, we will examine the Ga-In-As ternary system. A graduate student, H.D. Lee, is responsible for this segment of the work.

2. Experimental property data for group III-V solid solutions is scarce. In the past we have relied on the predictions of empirical (assessment results) or semiempirical (e.g., pseudopotential 
calculations, DLP model) for estimates of solid solution properties. Furthermure, these predictions give only the enthalpy of mixing. Recent results in the literature suggest that the solid solutions can have significant non-ideal entropies of mixing. Indeed, complete sub-lattice ordering has been observed in epitaxial films grown under certain conditions. As the order-disorder transformation has a strong influence on the optical properties of compound semiconductors, understanding the origin of ordering is important. Both thermodynamic and kinetic arguments have been proposed as the basis of this ordering. The thermodynamic analysis is hampered by a lack of accurate thermodynamic. properties. As originally proposed, we plan to measure activities in pseudobinary solid solutions with a solid state galvanic cell. The first system to be studied is $\mathrm{Ga}_{x} \mathrm{In}_{1-x}$ As with the working electrode material deposited by MOCVD. We recently observed ordering (by transmission electron diffraction) in MOCVD deposited $\mathrm{Ga}_{x} \mathrm{In}_{1-\mathrm{x}} \mathrm{As}$ on $\mathrm{InP}$ and this will be examined in our electrode materials (by high resolution diffractometry). To the best of our knowledge, this study is the first emf study on a III-V solid solution. This portion of the program will be performed by a Ph.D. student, S. Misra.

If time permits this year, we will then begin the coulometric titration experiments to determine the range of stoichiometry in GaAs. We pioneered this technique with AISb (see program report) and the results should have great scientific impact because of the direct relation to the point defect structure of GaAs.

3. One of the more important contribution:s we feel this program will make is in establishing a sund theoretical framework upon which to analyze the thermochemistry and phase diagrams of compound semiconductor systems. Our formulation of the problem involves two types of binary variables: $\theta_{\mathrm{AB}}=\left(\mu_{\mathrm{AB}}^{0,8}-\mu_{\mathrm{A}}^{0,1}-\mu^{0,1}\right) / \mathrm{RT}$ and $\Gamma_{\mathrm{AB}}=\gamma_{\mathrm{A}}^{1} \gamma_{\mathrm{B}}^{1} \gamma_{\mathrm{AB}}^{\mathrm{B}}$. We have derived basic equations which describe the liquidus and solidus for pseudobinary, ternary, pseudoternary and quaternary systems in terms of these variables. The $\Theta_{A B}$ term is a function of only pressure, temperature and choice of standard state. In the past the standard state has been chosen almost exclusively as the pure component at the temperature, pressure and phase of interest. As experimental characterization of this state for liquid $A s$ and $P$ is not possible since these elements sublime at 1 atm pressure. In the 
next year's activities we will examine the infinite dilution standard state as outlined in the original proposal. The advantages of this choice of reference state is that it is experimentally accessible and is appropriate for the technologically important group III-rich solutions.

Assessment work will also continue in the next year. As the U.S. representative of the international task force on III-V phase diagrams, we are charged with assessing the group III antimonide systems. Furthermore, the Ga-In-As system will be assessed as the experimental segment of this program is completed.

It is proposed to address a subject that was not originally proposed as described below. The commonly measured thermodynamic solution properties includ component activities, enthalpy of mixing, and the phase diagram. This data set is overdefined, given knowledge of the standard state properties. It is common, however, not to have a full data base for a particular system. Thus it is desirable to have procedures to estimate one property type from measurements of the other two types of properties. The literature contains a procedure for estimating activities from measurements of the enthalpy mixing and phase diagrams. The problem of calculating the phase diagrams from measurements of component activities and the enthalpy of mixing is trivial. The final problem, calculating the enthalpy of mixing from measured component activities and the phase diagram has not been formally addressed. We plan to develop the theoretical framework for this problem and test the method on selected data sets. The work described in this section will be performed by a Ph.D. student, S. Misra.

4. A final segment of the work proposed in the next year is the computation of chemical equilibria in group III-V systems. The first system to be treated is the Ga-In-As-P-Cl-H one, which is important in hydride CVD. We will also investigate the addition of $\mathrm{C}$ to the element list to investigate the possibilities of a new CVD chemistry: combined MOCVD and hydride CVD. A novel aspect of method of equilibrium computation is the inclusion of a first order sensitivity analysis. The results of the sensitivity analysis permits one to judge the confidence of the results and suggests which species requires a better thermodynamic property definition. This last aspect can serve as a guideline 
for prioritizing future studies in the community: A graduate student, C. Park, will compute the equilibria as his Ph.D. thesis is focused on CVD of compound semiconductors. 


\section{Personnel}

The program has involved several personnel since its initiation in 1986 as summarized below:

\section{Past Personnel}

John Krawczyk, M.S., 1988; currently at Kellogg

Corinne Coughanowr, Ph.D. 1989; currently post-doctoral associate at Uni 'ersity of Grenohle, France

Brian Sears, Ph.D. 1990; will enroll in medical school at Ohio State University in Fall

Professor Ali Khan, Universided de Oriento, Cumana, Venezuela; spent 1 year in laboratory while on sabbatical

Dr. Francoise DeFoort, Framatome, Lyon, France, Post-doctoral Associate for 1 year

Professor Yves Feutelais, Universite Paris-Sud, France; visiting faculty for two months

\section{Current Students}

Sudhanshu Misra, B.S. I.I.T Madra, 1987, M.S. Colorado St. University, 1989

Chinho Park, B.S. Honyang Univ., 1981, M.S. Seoul Nat. University, 1983

H.D. Lee, B.S. Yon-Sei Univ., 1984, M.S. Univ. Florida, 1986

We have made liberal use of undergraduate students, several of whom were on work study programs. They have been involved in literature searches, implantation of computer code, and assisting in the laboratory. Such an experience is important in their education and their involvement will continue in the next funding period. 


\section{Current Support: P.I.}

1. "Investigation of Temperature and Concentration Oscillations in the Directional Solidification of $\mathrm{Pb}-\mathrm{Sn}-\mathrm{Te} ", \mathrm{NASA}, 1 / 1 / 90$ to $12 / 31 / 90$. Funding of $\$ 59,504$ for 1 year. Co-P.I. R. Narayanan, Dept. Chem. Eng.

\section{Current Supporti Co-P.I.}

1. "Florida Initiative in Microelectronics and Advanced Materials Program", DARPA, 10/1/89 to $9 / 30 / 90$. This program involves approximately 60 faculty in the Florida State University system and will terminate $9 / 30 / 90$.

\section{Pending Support}

1. "Center for the Development of Commercial Crystal Growth in Space", NASA, Funding request $\$ 200,000$. P.I. R. Abbaschian with 3 co-P.I.'s. Approval has been granted and grant terms currently under negotiation. 

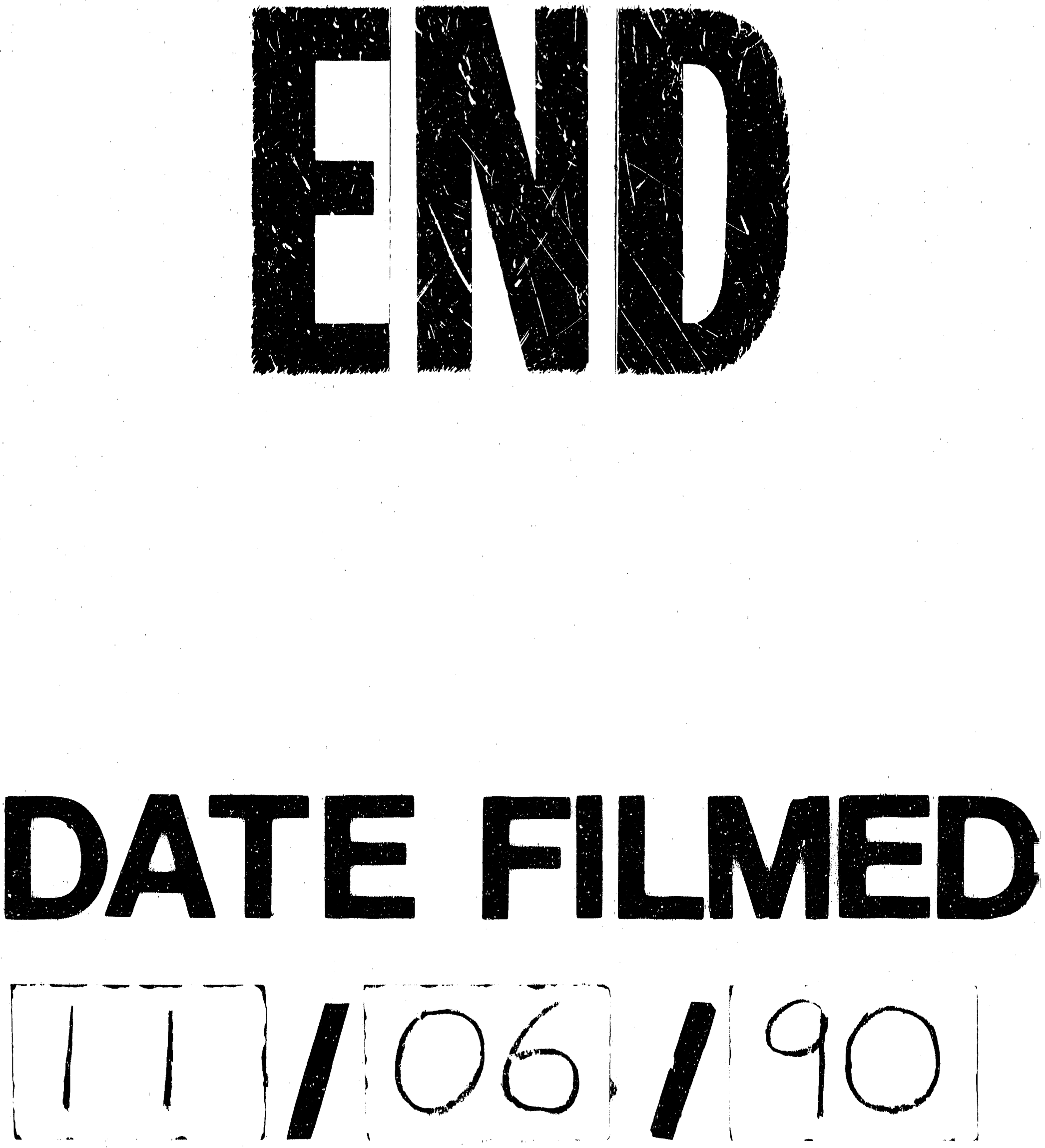

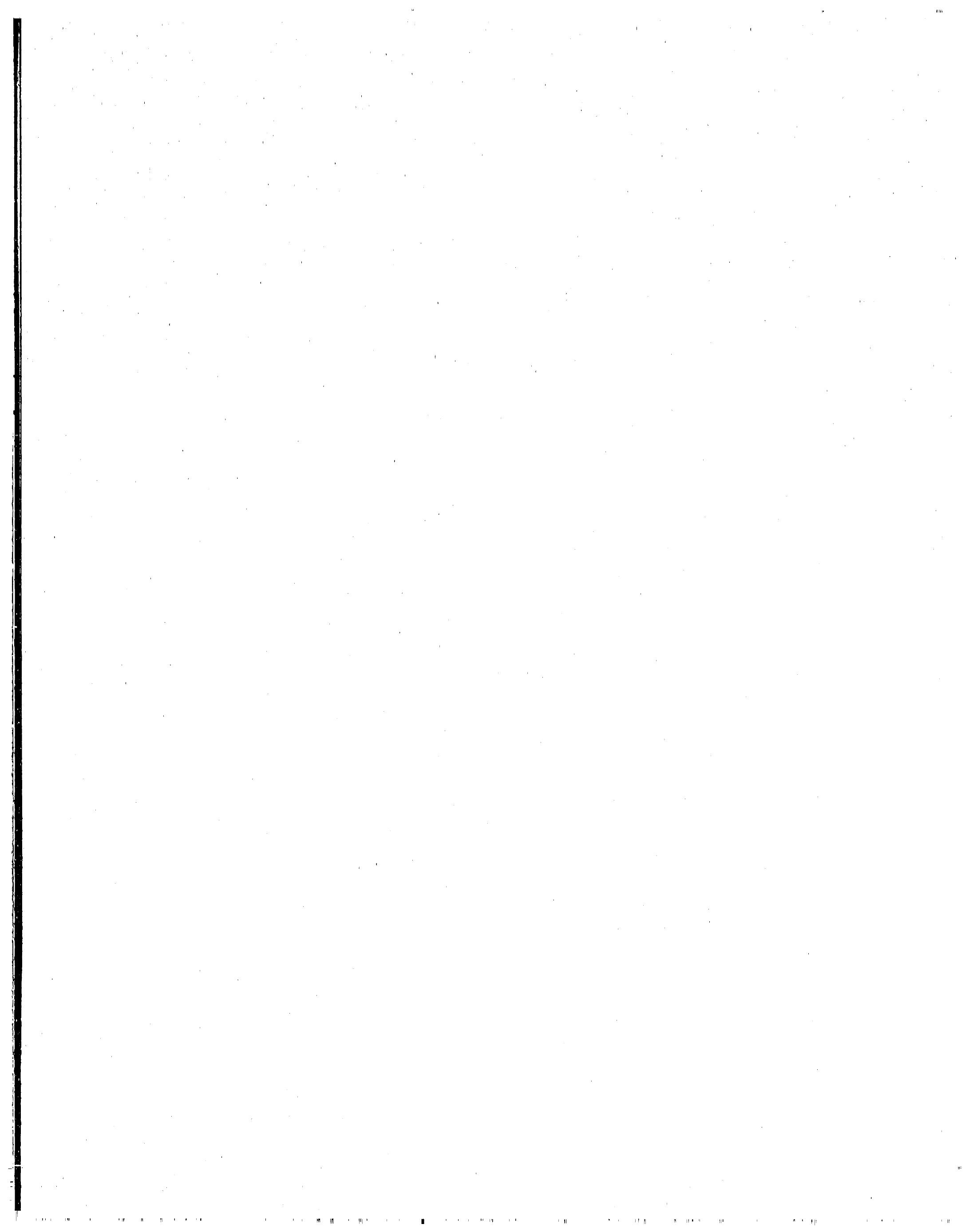